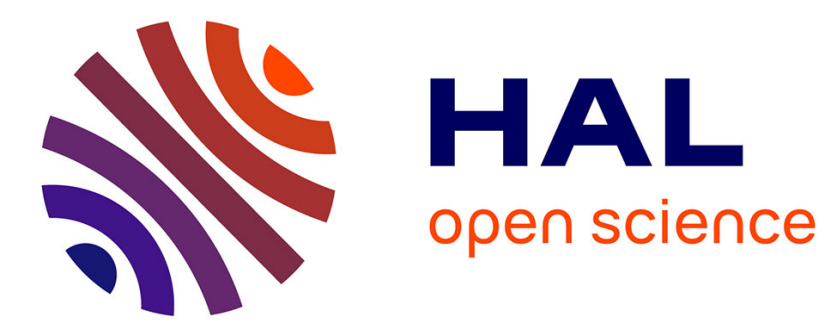

\title{
Low energy dissociation processes of ionized cyclohexene: a theoretical insight
}

Guy Bouchoux, Jean-Yves Salpin, Manuel Yáñez

\section{To cite this version:}

Guy Bouchoux, Jean-Yves Salpin, Manuel Yáñez. Low energy dissociation processes of ionized cyclohexene: a theoretical insight. Journal of Physical Chemistry A, 2004, 108 (45), pp.9853-9862. 10.1021/jp0480697 . hal-00068619

\section{HAL Id: hal-00068619 https://hal.science/hal-00068619}

Submitted on 4 Oct 2018

HAL is a multi-disciplinary open access archive for the deposit and dissemination of scientific research documents, whether they are published or not. The documents may come from teaching and research institutions in France or abroad, or from public or private research centers.
L'archive ouverte pluridisciplinaire HAL, est destinée au dépôt et à la diffusion de documents scientifiques de niveau recherche, publiés ou non, émanant des établissements d'enseignement et de recherche français ou étrangers, des laboratoires publics ou privés. 


\title{
Low energy dissociation processes of ionized cyclohexene: a theoretical insight.
}

\author{
Guy Bouchoux ${ }^{1}$, Jean-Yves Salpin² and Manuel Yáñez ${ }^{3}$. \\ 1) Laboratoire des Mécanismes Réactionnels, UMR CNRS 7651, Ecole Polytechnique, \\ F- 91128 Palaiseau cedex, France \\ 2) Laboratoire Analyse et Environnement, UMR 8587, Institut des Sciences, Université d'Evry, boulevard F. \\ Mitterrand, 91025 Evry cedex, France \\ 3) Departamento de Quimica. Universidad Autonoma de Madrid \\ Cantoblanco 28049 Madrid (Spain)
}

\begin{abstract}
The major dissociation reactions of the cyclohexene radical cation, $\mathbf{1}$, lead to cyclopentenyl ion by methyl loss and to ionized 1,3-butadiene after elimination of $\mathrm{C}_{2} \mathrm{H}_{4}$. These two reactions are also observed during the Diels-Alder reaction between ionized butadiene and ethene in the gas phase. The energetic and mechanistic aspects of the methyl loss process from cyclohexene radical cation or reaction between ionized butadiene and ethene are discussed with the help of molecular orbital calculations at the B3LYP/6-311+G(3df,2p)//B3LYP/6-31G(d) levels. Methyl loss is demonstrated to result from successive 1,2-hydrogen shifts and ring-contraction/ring-opening steps involving, as a crucial intermediate, ionized bicyclo $[1,3,0]$ hexane rather than the distonic ion $\left[\mathrm{CH}_{2} \mathrm{CH}_{2} \mathrm{CHCHCHCH}_{2}\right]^{\circ+}$ (one of the open forms of ionized cyclohexene). This latter is however involved during the direct and retro Diels-Alder reactions. The $\mathrm{CH}_{3}$ and $\mathrm{C}_{2} \mathrm{H}_{4}$ losses rate curves of the cyclohexene ion are calculated using the RRKM equation and the molecular orbital calculations results. These estimations allow the understanding of the experimental observations concerning dissociations of the cyclohexene radical cation, $\mathbf{1}$, and the collision complex formed between ionized butadiene and ethene.
\end{abstract}




\section{Introduction}

Cation radical Diels-Alder cycloadditions, both in the condensed and in the gas phase, have been the subject of intense interest during the past two decades ${ }^{1-9}$. Surprisingly however, the parent reaction has been explored in only a limited number of experimental ${ }^{4-6}$ and theoretical studies ${ }^{7-10}$. The present status of our knowledge of the gas phase reaction between ionized 1,3-butadiene and ethene may be summarized as follows. Starting from thermalized reactants in an ion cyclotron resonance mass spectrometer, two ionized products were identified, namely cyclopentenyl cation and 1,3-butadiene radical cation resulting from a methyl loss and a methylene exchange, respectively (Scheme 1) ${ }^{4}$. Deuterium labeling experiments reveal that the methyl loss is preceded by a quasi complete H/D scrambling inside the transient collision complex and that the ethylene molecule eliminated during the second reaction contains specifically one methylene group from the terminal position of the 1,3-butadiene radical cation (1 or $\left.1^{\prime}\right)$ and the other from the initial neutral reactant (3 or 3 ').

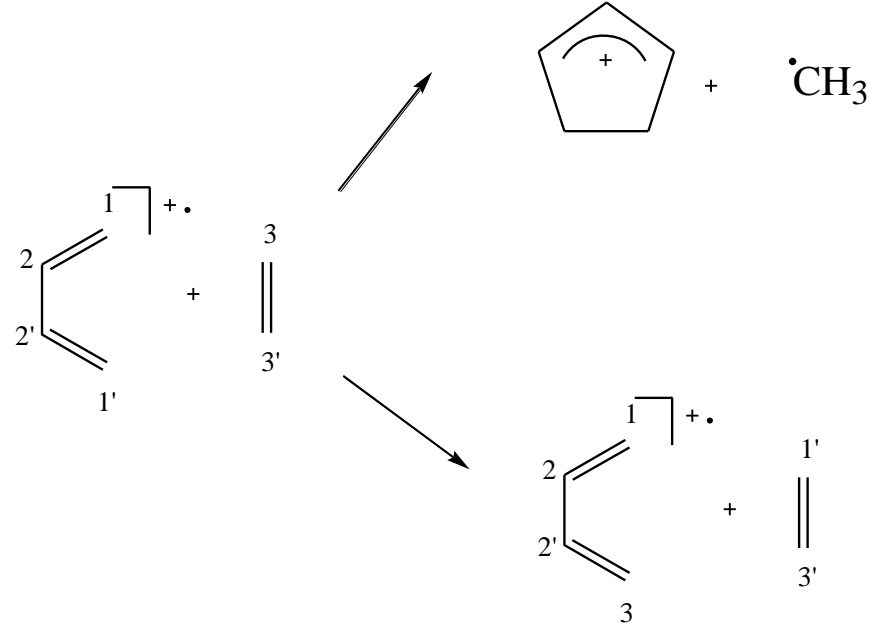

Scheme 1

Identification of the cyclopentenyl ion structure has been possible from the determination of its deprotonation energy (i.e. the proton affinity of the conjugate base) experimentally, by the thermokinetic method, and theoretically, by G2MP2 molecular orbital calculations ${ }^{5}$. Under the very low pressure which prevail in the ICR experiments, 
the transient collision complexes have generally not enough time to be collisionally relaxed to their ground state before dissociation and so they are not detected. It is consequently difficult to characterize during an ICR experiment the various intermediates involved during the reactions depicted in Scheme 1. What is sure however is that all the parts of the potential energy surface explored by the system during these processes are necessarily situated below the energy level of the reactants. This thermochemical criteria, together with the results of the deuterium labeling, may be used to find reasonable pathways by means of molecular orbital calculations. This approach, suggested in our original paper ${ }^{4}$, has been used by Hofmann and Schaefer ${ }^{8}$ and will be discussed later in this study. Recently, the 1,3-butadiene radical cation and ethene reaction has been carried out under high pressure conditions in a flowing afterglow apparatus ${ }^{6}$. In these conditions, adduct ions $\left[\mathrm{C}_{6} \mathrm{H}_{10}\right]^{+}$were detected and characterized by collisions in a triple quadrupole analyzer. Using the appearance curve for the formation of $\left[\mathrm{C}_{5} \mathrm{H}_{7}\right]^{+}$ion, and by comparison with a set of $\mathrm{C}_{6} \mathrm{H}_{10}$ precursors (1,3-, 2,4- and 2,4-hexadiene, 2,3-dimethyl-butadiene, 3-methyl-1,3-pentadiene, cyclohexene, 1-methyl-cyclopentene and methylene cyclopentane), the authors proposed that the $\left[\mathrm{C}_{6} \mathrm{H}_{10}\right]^{+}$adducts possess a 2,4-hexadiene structure.

Formally, the radical cation reaction between ethene and 1,3-butadiene radical cation (Scheme 1), is expected to yield the cyclohexene radical cation, $\mathbf{1}$, according to the time honored Diels-Alder process. The behavior of the latter radical cation has been studied since a long time ${ }^{11-19}$. Its major dissociation route, as well as many other $\left[\mathrm{C}_{6} \mathrm{H}_{10}\right]^{+}$ions ${ }^{14,15}$, leads to $\left[\mathrm{C}_{5} \mathrm{H}_{7}\right]^{+}$ion (Scheme 2).

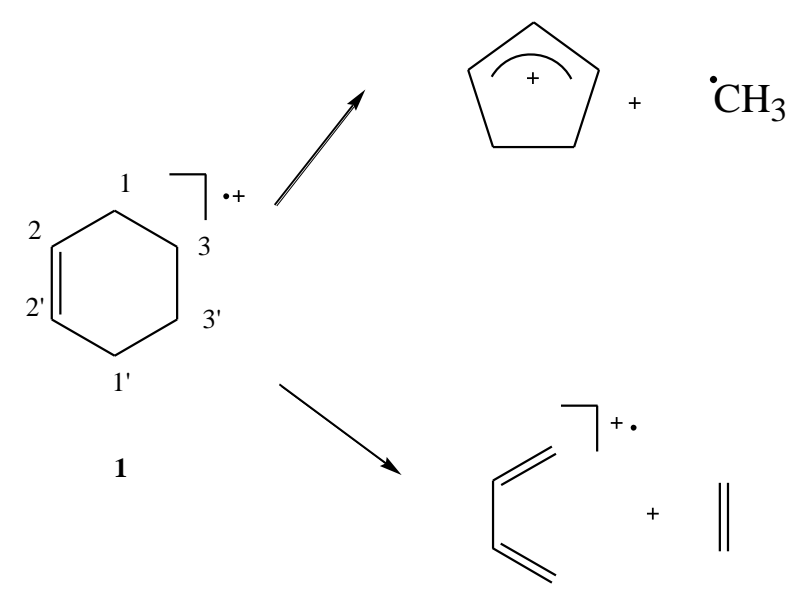

Scheme 2 
It is noteworthy that the methyl loss is the lowest energy pathway and that the $\mathrm{AE}\left[\mathrm{C}_{5} \mathrm{H}_{7}\right]^{+}$, from cyclohexene, measured by Winters and Collins ${ }^{17}$, by Traeger and Lossing $^{19}$ and by $\mathrm{Li}$ and $\mathrm{Baer}^{20}$ are within $\sim 0.1 \mathrm{eV}$ and point to the formation of cyclopentenyl ion at its thermochemical threshold. Moreover, the exclusive formation of cylopentadienyl structure has also been established from deprotonation energie determination $^{5}$. Deuterium labeling shows that this fragmentation is preceded by a complete H/D exchange when low internal energy precursors are sampled ${ }^{11-14}$, by contrast, a preferred elimination of a methyl containing a methylene in position 1(1') (Scheme 2) is noted at short observation time (i.e. at energy high enough to attain a dissociation rate of $\left.\sim 10^{11} \mathrm{~s}^{-1}\right) .11-13$

The second dissociation pathway of cyclohexene radical cation, $\mathbf{1}$, is the so-called retro Diels-Alder fragmentation which regenerate 1,3-butadiene radical cation and ethene (Scheme 2). Again, appearance energy determinations point to the formation of the dissociation products close to their thermochemical threshold ${ }^{17,20}$. Information provided by the deuterium labeling indicates a preference for the elimination of $\mathrm{C}_{2} \mathrm{H}_{4}$ containing the hydrogen atoms in positions 3 and 3' at high internal energy, and a statistical distribution of the labels at low internal energy. This latter phenomenon has been suggested to originate from 1,3 allylic hydrogen shifts on the intact cyclohexene ring ${ }^{11-13}$. Direct and reverse cation radical Diels-Alder reactions have been investigated using ab initio molecular orbital calculations by Bauld ${ }^{7}$, Hofmann and Schaefer ${ }^{8,9}$ and Haberl et al ${ }^{10}$. The authors conclude to the occurrence of stepwise processes connecting ionized cyclohexene, $\mathbf{1}$, with 1,3-butadiene radical cation plus ethene via an open chain distonic intermediate situated $\sim 140 \mathrm{~kJ} / \mathrm{mol}$ above ionized cyclohexene.

Despite these valuable experimental and theoretical information several important questions remain unanswered. In particular, what is the mechanism of the methyl elimination from ionized cyclohexene, 1? Further, is this mechanism applicable to the methyl elimination observed in the reaction between 1,3-butadiene radical cation and ethene? Finally, what is the involvement of ionized cyclohexene, 1, and ionized 2,4-hexadiene, during the radical cation Diels-Alder process? 
The goal of the present study is thus to bring new theoretical results answering these fundamental questions. As shown below, a new and complete interpretation of the lowest energy routes followed by ionized cyclohexene, $\mathbf{1}$, and the reactants of the parent Diels-Alder reaction will be proposed. It is based on a large investigation of the potential energy profile connecting the various species considered by means of density functional theory (DFT) molecular orbital calculations at the B3LYP/6-311+G(3df,2p)// B3LYP/6-31G(d) level. Our results emphasize the key role of bicyclo[3,1,0]hexane, methyl-1- and methyl-3-cyclopentene and their 1,3-diyl(distonic) isomers during the isomerization processes. A rationalization of the available data will be discussed in the light of these results and on statistical rate constant calculations.

\section{Computational section}

The potential energy profile associated with the direct and reverse Diels-Alder processes and to the methyl loss reaction leading to cyclopentenyl cation has been examined using the DFT method at the B3LYP/ 6-31G(d) level. Zero point vibrational energies were estimated at this level and more accurate energies have been obtained from single point calculations at the B3LYP/6-311+G(3df,2p) level. All calculations have been undertaken using the Gaussian98 suite of programs ${ }^{21}$.

Insert adenda2

\section{Results and Discussion}

\section{The thermochemical frame}

Since thermochemistry dictates the feasibility of the observed reaction processes a brief summary of the presently available data is given as a preamble. Heats of formation obtained at $298 \mathrm{~K}$ and $0 \mathrm{~K}$ for cyclohexene radical cation, 1, and its dissociation products are presented in Table 1.

Table 1 
Appearance energies of the $\left[\mathrm{C}_{5} \mathrm{H}_{7}\right]^{+}$and $\left[\mathrm{C}_{4} \mathrm{H}_{6}\right]^{+}$fragment ions originating from cyclohexene have been determined in the 1970's from electron ionization experiments ${ }^{17-19}$. As recalled in the Introduction, the methyl loss is the lowest energy pathway of the two competitive channels. Winters and Collins ${ }^{17}$ utilized the energy distribution difference method of determination of appearance energies after calibration of the energy scale with krypton and xenon. They obtained $\mathrm{AE}\left[\mathrm{C}_{5} \mathrm{H}_{7}\right]^{+}$and $\mathrm{AE}\left[\mathrm{C}_{4} \mathrm{H}_{6}\right]^{+{ }^{+}}$values of 10.18 and 10.67 $\mathrm{eV}$, respectively, and an ionization energy $\mathrm{IE}($ cyclohexene) of $8.92 \mathrm{eV}$, in excellent agreement with the $8.95 \mathrm{eV}$ value obtained by photoelectron of photoionization experiments $^{22,23}$. Using a monoenergetic electrons beam device, Traeger and Lossing ${ }^{19}$ obtained $\mathrm{AE}\left[\mathrm{C}_{5} \mathrm{H}_{7}\right]^{+}=10.26 \mathrm{eV}$, in correct agreement with Winter and Collins ${ }^{17}$. By contrast, Praet ${ }^{18}$, who used the extrapolated voltage difference method, reports AE energies higher by ca. $1.0 \mathrm{eV}$ than the preceding authors. The reason of this discrepancy lies probably in a wrong calibration of the energy scale since the cyclohexene ionization energy is itself overestimated by $\sim 0.6 \mathrm{eV}$ in the Praet's report ${ }^{18}$. More recently, $\mathrm{Li}$ and Baer ${ }^{20}$ explored the behavior of cyclohexene by threshold photoelectron-photoion coincidence spectroscopy, they obtained AE values for both $\left[\mathrm{C}_{5} \mathrm{H}_{7}\right]^{+}$and $\left[\mathrm{C}_{4} \mathrm{H}_{6}\right]^{+{ }^{+}}$within $\sim 0.1 \mathrm{eV}$ of the results by Winter and Collins ${ }^{17}$ and Traeger and Lossing ${ }^{19}$.

If we roughly consider that the appearance energies ${ }^{17,19}$ correspond to the $0 \mathrm{~K}$ enthalpy difference between the products and the cyclohexene molecule, relative $\Delta \mathrm{H}^{\circ}{ }_{0}$ of 123 and $166 \mathrm{~kJ} / \mathrm{mol}$ (with a probable error of ca. $10 \mathrm{~kJ} / \mathrm{mol}$ ) are obtained for the methyl loss and the ethene loss, respectively. It is clear from examination of Table 1 that these values match closely the expected enthalpy differences for formation of cyclopentyl cation and ionized 1,3-butadiene at their thermochemical thresholds.

A corollary observation is that all the reaction intermediates and transition structures separating 1 from its dissociation products should lie below a 298K enthalpy of 990 $\mathrm{kJ} / \mathrm{mol}$ for the methyl loss and $\sim 1040 \mathrm{~kJ} / \mathrm{mol}$ for the retro Diels-Alder reaction. This leaves opened the route for isomerisation into a lot of stable structures, such as ionized allenes, 
dienes, cyclopentane or cyclobutane derivatives, as attested by the tabulation of their heats of formation ${ }^{22,23}$. What seems to be excluded however is the passage trough acetylenic structures before the methyl loss.

The lowest energy route for the methyl loss from cyclohexene radical cation 1

In 1999, Hofmann and Schaefer ${ }^{8}$ investigated pathways for the methyl loss from the adduct formed during the Diels Alder reaction between 1,3-butadiene radical cation and ethene. The pathway of lowest energy identified by the authors at the $\mathrm{UCCSD}(\mathrm{T}) / \mathrm{DZP} / / \mathrm{UMP} 2 / \mathrm{DZP}+\mathrm{ZPE}$ level of theory is summarized in Scheme 3.

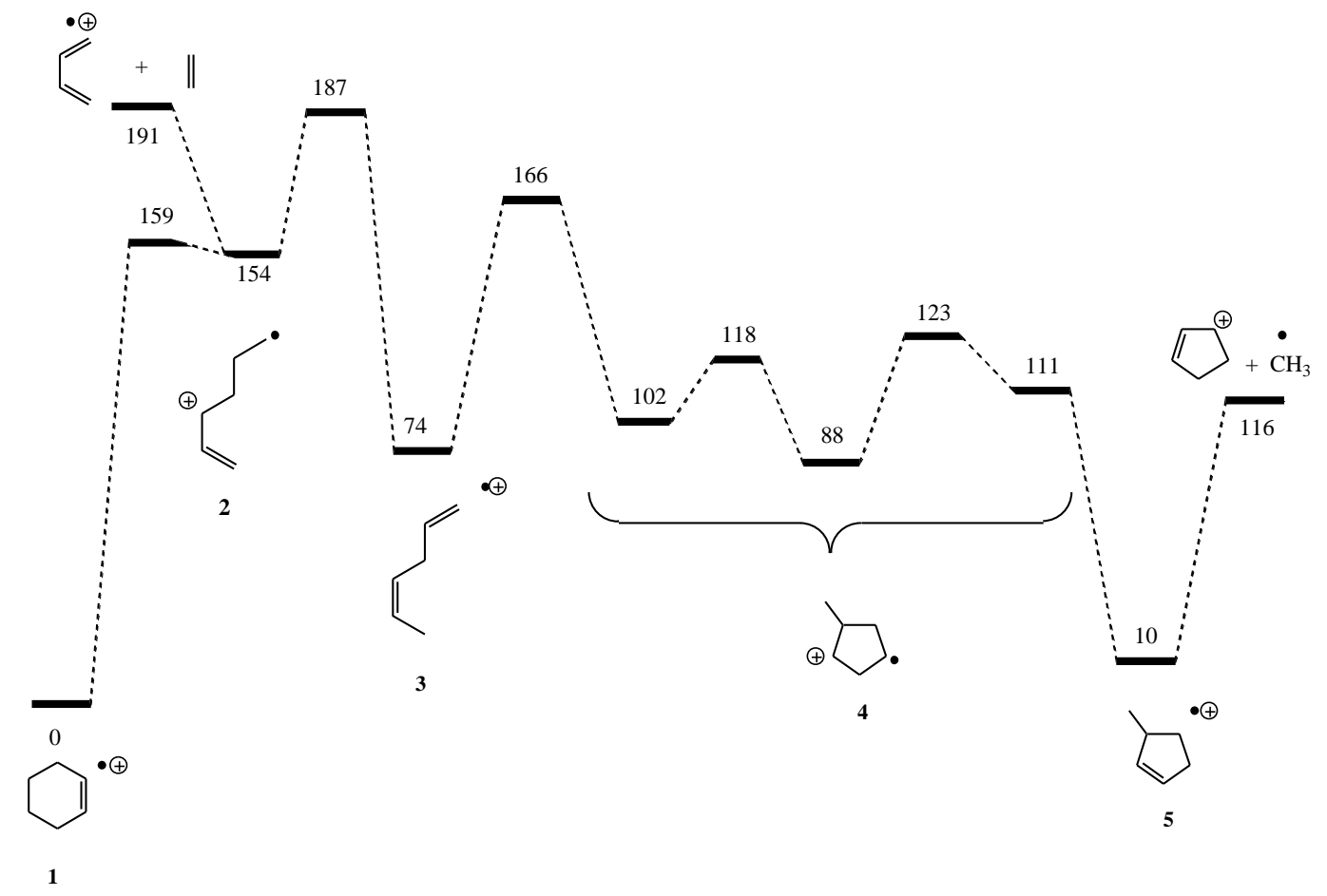

Scheme 3

During this process, ethene adds to the 1,3-butadiene radical cation to form the distonic intermediate 2 which undergoes a 1,5- $\mathrm{H}$ migration leading to the 1,4-hexadiene radical cation 3. Intramolecular cyclisation produces various forms of the 1,3-diyl(distonic) methyl cyclopentane intermediate 4 in which a 1,2-H shift gives rise to the 3-methyl cyclopentene radical cation, 5, the obvious precursor of the dissociation products, 
cyclopentenyl cation plus $\mathrm{CH}_{3}$. Formation of cyclohexene radical cation 1 from the distonic ion $\mathbf{2}$ has been shown to need practically no critical energy by the same authors ${ }^{9}$.

It is clear that the reaction sequence presented in Scheme 3 does not provide a correct basis for the interpretation of the behaviour of ionized cyclohexene $\mathbf{1}$ since the appearance energy determinations point to the formation of cyclopentenyl cation plus $\mathrm{CH}_{3}$ at their thermochemical threshold. i.e.. In fact, according to UCCSD(T)/DZP//UMP2/DZP+ZPE calculations, the dissociation products are situated $116 \mathrm{~kJ} / \mathrm{mol}(119 \mathrm{~kJ} / \mathrm{mol}$ experimental, see Table 1) above 1 and consequently even the first step of the above process, i.e. the ring opening $\mathbf{1} \rightarrow \mathbf{2}$, should be excluded because of its too large energy requirement! We thus investigate other reaction paths such as hydrogen migrations and ring contractions with the objective to find processes which need less energy than the upper limit of $\sim 120 \mathrm{~kJ} / \mathrm{mol}$.

The corresponding total and relative energies obtained during the present study at the B3LYP/6-311+G(3df,2p)//B3LYP/6-31G(d)+ZPE level are gathered in Table 2 and key structures are given in the supporting information.

Table 2

Figure 1

The first considered elementary steps, starting from ionized cyclohexene 1, are presented in Schemes 4 and 5.

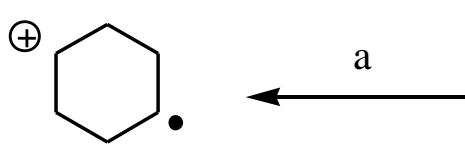

6

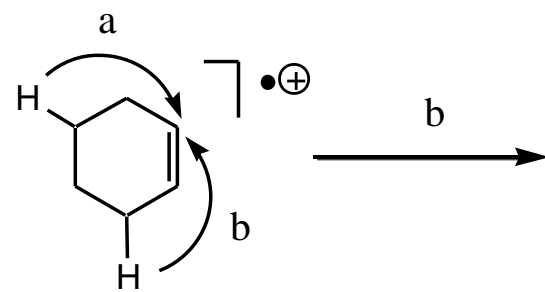

1<smiles>CCCCCCCCCCCC</smiles>

$1^{\prime}$

Scheme 4 
The degenerate 1,3-H shift $\mathbf{1} \rightarrow \mathbf{1}^{\prime}$ (Scheme 4) has been studied by Hofmann and Schaefer $^{8}$ who find a critical energy of ca. $170 \mathrm{~kJ} / \mathrm{mol}$, a clearly too high value to retain this reaction. Similarly the external 1,3-H shift $\mathbf{1} \rightarrow \mathbf{6}$ leading to 1,4-diyl(distonic) cyclohexane radical cation 6 is associated with a too large critical energy $(138 \mathrm{~kJ} / \mathrm{mol})$.

By contrast, the formation of the 1,3-diyl(distonic) cyclohexane radical cation 7 via a 1,2- $\mathrm{H}$ shift from $\mathbf{1}$ appears to be possible (Scheme 5). At the B3LYP/6-311+G(3df,2p)//B3LYP/6-31G(d)+ZPE level, this reaction, $1 \rightarrow 7$, passes trough a transition structure situated $71 \mathrm{~kJ} / \mathrm{mol}$ above $\mathbf{1}$ and leads to the 1,3-diyl cyclohexane radical cation 7, a structure which appears to be only weakly stabilized (4 $\mathrm{kJ} / \mathrm{mol}$ ) with respect to the transition structure $1 / 7$. Another pathway for the formation of ion 7 is the 1,4-hydrogen migration, $\mathbf{1} \rightarrow \mathbf{7}$, indicated in Scheme 5. This reaction however needs a constrained folding of the cyclohexene skeleton which results in a critical energy as high as $185 \mathrm{~kJ} / \mathrm{mol}$, a clearly too large value to be considered here.

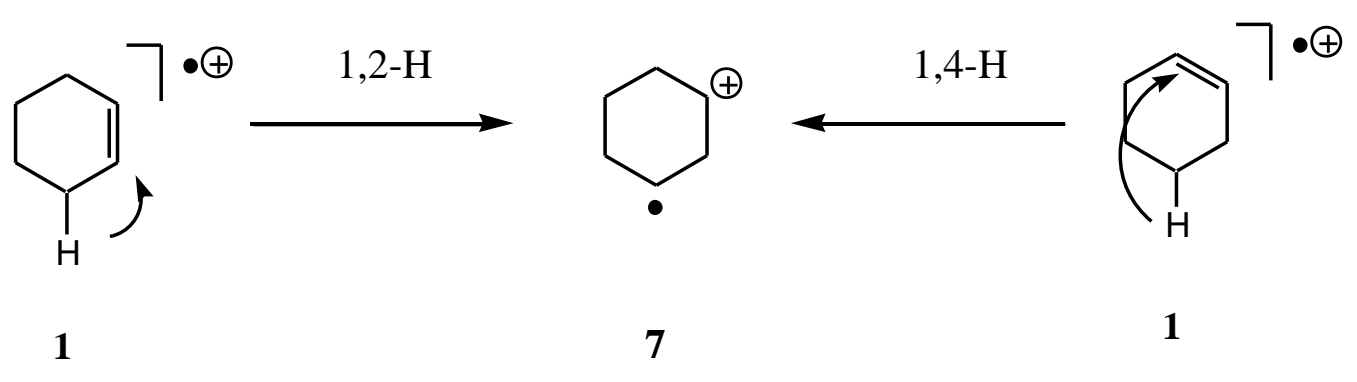

Scheme 5

If the direct generation of the 1,4-diyl(distonic) cyclohexane radical cation $\mathbf{6}$ from $\mathbf{1}$ may reasonably be excluded, its formation from 7 appears to be feasible. Accordingly, the isomerisation $\mathbf{7} \rightarrow \mathbf{6}$ by a $1,2-\mathrm{H}$ shift passes by a transition structure of $106 \mathrm{~kJ} / \mathrm{mol}$ relative energy. The 1,4-diyl(distonic) cyclohexane radical cation $\mathbf{6}$ is then produced in a quasi planar conformation situated $71 \mathrm{~kJ} / \mathrm{mol}$ above $\mathbf{1}$ and isomerises easily to its more stable chair conformer $(66 \mathrm{~kJ} / \mathrm{mol}$ relative energy). These two conformers are connected by a quite low energy barrier, 6 (planar) $\rightarrow \mathbf{6}$ (chair), of $2 \mathrm{~kJ} / \mathrm{mol}$.

Two other structures keeping the cyclohexane ring arrangement have been finally considered: the bicyclo[3,1,0]hexane, $\mathbf{8}$, and the cyclohexyl carbene $\mathbf{9}$ (Scheme 6). 


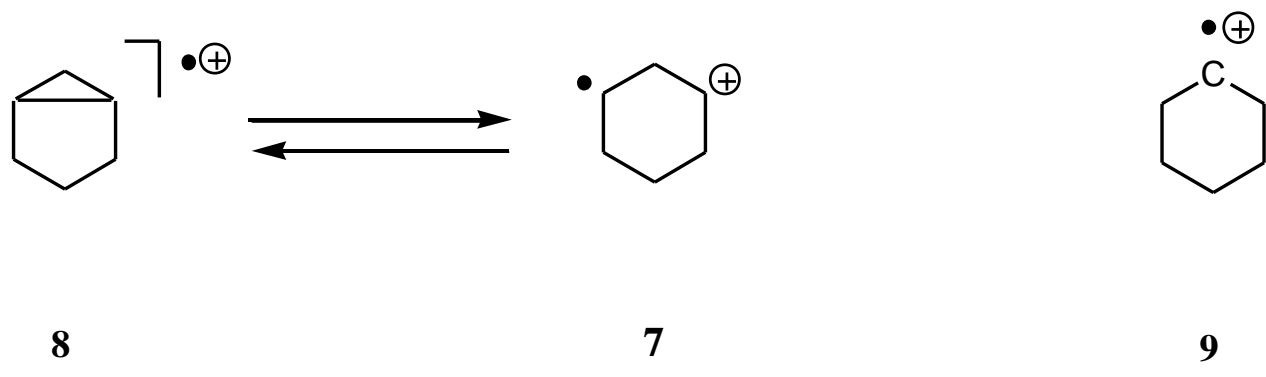

Scheme 6

B3LYP/6-311+G(3df,2p)//B3LYP/6-31G(d)+ZPE calculation places radical cations 8 and 942 and $158 \mathrm{~kJ} / \mathrm{mol}$ above $\mathbf{1}$. Thus the latter carbenoid ion should not be retained as a possible reaction intermediate while $\mathbf{8}$ constitute obviously a favorable candidate. Furthermore, calculation shows that the ring closure $\mathbf{7} \rightarrow \mathbf{8}$ may occur slightly below the upper thermochemical limit since the transition structure $\mathbf{7 / 8}$ possesses a relative energy equal to $105 \mathrm{~kJ} / \mathrm{mol}$. A similar ring closure of the 1,4-diyl ion 6 to give ionized bicyclo[2,2,0]hexane has been excluded because experimental thermochemistry indicates that the latter ion is $135 \mathrm{~kJ} / \mathrm{mol}$ above ionized cyclohexane $\mathbf{1}^{22,23}$.

At this stage, it appears that the most easily accessible structure from 1, en route to the methyl loss, is the 1,3-diyl cyclohexane radical cation $\mathbf{7}$ which in turn may isomerise to $\mathbf{6}$ or 8 . The possible evolutions of the distonic ion $\mathbf{6}$ should involve the breaking of one of the $\mathrm{C}(2) \mathrm{C}(3)$ bond as presented in Scheme 7.

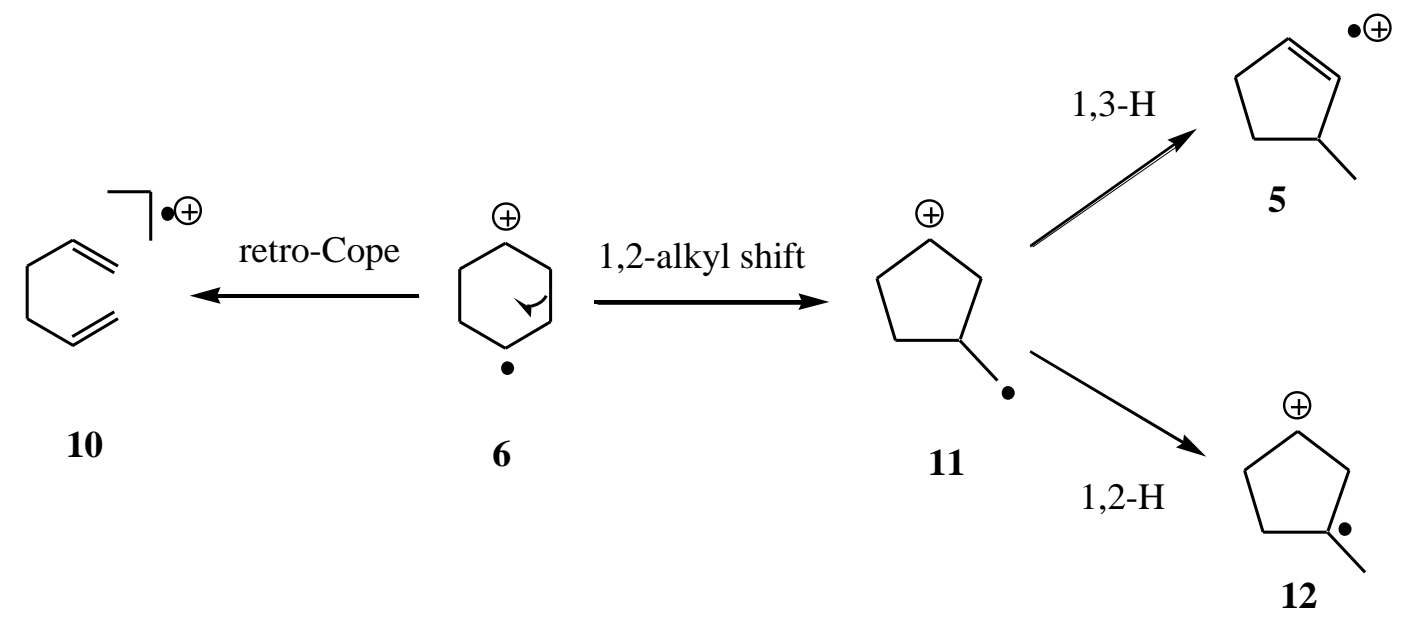

Scheme 7 
The simple ring opening of ion 6 (the retro-Cope reaction) leads to ionized 1,5-hexadiene, 10. However, the experimental heat of formation of $\mathbf{1 0}$ is $120 \mathrm{~kJ} / \mathrm{mol}$ higher than that of ionized cyclohexene and, therefore, this reaction is probably unlikely to occur before methyl loss. This hypothesis is not entirely corroborated by the calculations. Accordingly, at the B3LYP/6-311+G(3df,2p)/B3LYP/6-31G(d) level the relative energy of $\mathbf{1 0}$ is only $84 \mathrm{~kJ} / \mathrm{mol}$ and that of the transition structure $\mathbf{6} \rightarrow \mathbf{1 0}$ equal to $96 \mathrm{~kJ} / \mathrm{mol}$. The second possible evolution of $\mathbf{6}$ consists in a $\mathrm{C}(2) \mathrm{C}(3)$ bond breaking coupled with a $\mathrm{C}(2) \mathrm{C}(4)$ bond forming. This 1,2-alkyl shift generates the 3-methylene cyclopentyl distonic ion 11 whose calculated relative energy $(119 \mathrm{~kJ} / \mathrm{mol})$ is close to the upper thermochemical limit. Isomerisation of $\mathbf{1 1}$ by 1,3 or 1,2-H shift in order to produce either ionized 3-methyl cyclopentene, 5, or ionized 1,3-diyl methyl cyclopentane, 12 (Scheme 7) are high energy processes. The energies of the corresponding transition structures $\mathbf{5 / 1 1}$ and 11/12 are calculated to be 141 and 171 respectively; this clearly excludes the participation of $\mathbf{1 1}$ in the searched reaction pathway.

It remains to explore the reaction potentialities of the bicyclo[3,1,0]hexane structure, $\mathbf{8}$. The behavior of such a species, bearing an ionized cyclopropane ring, is expected to rely to the weakness of this structural moiety. The "internal" cyclopropane ring opening, $8 \rightarrow 7$ which has been discussed above enters into this category. The other possibility is the "side" cyclopropane ring opening which would give rise to the 2-methylenecyclopentyl distonic ion 13 (Scheme 8).

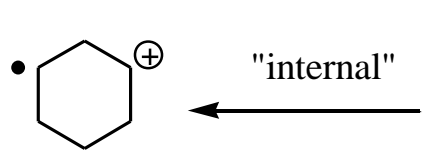

7
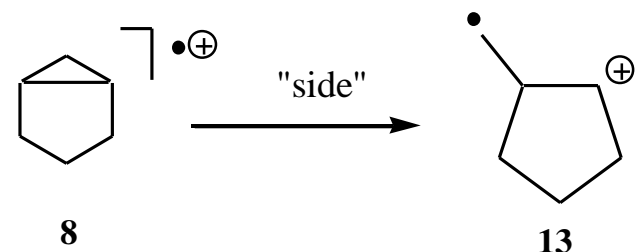

Scheme 8

This latter reaction is the most favored one, its transition structure $(72 \mathrm{~kJ} / \mathrm{mol}$ relative energy) is very close in structure and in energy to the distonic ion $\mathbf{1 3}(71 \mathrm{~kJ} / \mathrm{mol}$ relative energy).

The remaining part of the travel consists, starting from 13, in successive hydrogen 
migrations on the methyl cyclopentane skeleton in order to produce ionized 3-methyl cyclopentene, $\mathbf{5}$, the most likely precursor of the $\left[\mathrm{C}_{5} \mathrm{H}_{7}\right]^{+}$cyclopentenyl fragment ion. The least energy route, presented in Scheme 9, involves exclusively 1,2-H shifts.

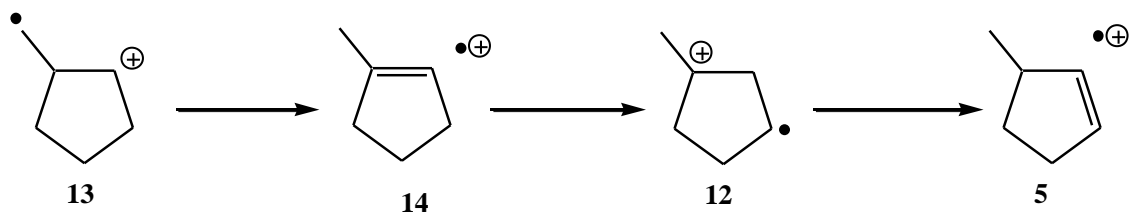

Scheme 9

The highest transition structure corresponds to the step $\mathbf{1 3} \rightarrow \mathbf{1 4}$ its relative energy (111 $\mathrm{kJ} / \mathrm{mol})$ is very close to the energy level of the dissociation products $(106 \mathrm{~kJ} / \mathrm{mol}$ calculated, $123 \mathrm{~kJ} / \mathrm{mol}$ experimental). Structures $\mathbf{1 4}$ and $\mathbf{5}$ are the most stable species bearing a cyclopentane skeleton, their relative energies are -41 and $8 \mathrm{~kJ} / \mathrm{mol}$, respectively. Interconversion of $\mathbf{5}$ and $\mathbf{1 4}$ via the distonic intermediate $\mathbf{1 2}$ is a facile process, the top of the overall energy barrier (corresponding to the $\mathbf{1 4} \rightarrow \mathbf{1 2}$ step) is $40 \mathrm{~kJ} / \mathrm{mol}$ below the dissociation products.

Other reactions were explored in the vicinity of structures 12 and 13 (Scheme 10). For example, isomerization of the methylene 2-cyclopentyl cation $\mathbf{1 3}$ by 1,2 and 1,3-H shifts leading to 3-methylene cyclopentyl ion $\mathbf{1 1}$ and the carbenic ion 16; formation of 3-methylene cyclopentyl ion $\mathbf{1 1}$ by 1,2-H shift from $\mathbf{1 2}$ or involvement of ionized methylenecyclopentane $\mathbf{1 6}$ by cyclisation of cyclohexyl carbene $\mathbf{9}$ formed by a 1,3-H migration inside the precursor $\mathbf{8}$. All these possibilities should be excluded on the basis of their too energetic transition structures or even, in some cases, of the too high relative energy of the stable species itself (eg. 9 and 16) (see Table 2). One should note, that reaction $13 \rightarrow \mathbf{1 5}$ is associated with a very low critical energy and thus the latter structure may be easily produced. However it constitutes a cul de sac in the present part of the potential energy surface since its isomerisation into ionized 3-methylcyclopentene 5 needs $180 \mathrm{~kJ} / \mathrm{mol}$ critical energy ${ }^{8}$. 


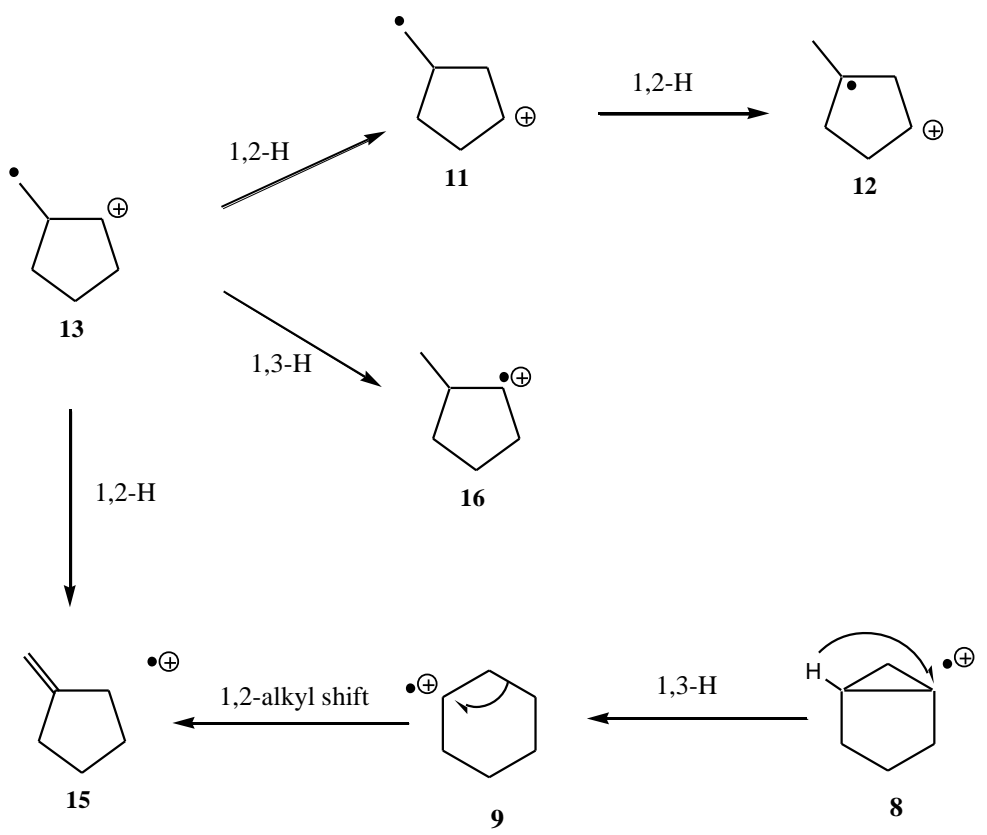

Scheme 10

In summary, the lowest energy route for methyl loss from ionized cyclohexene, $\mathbf{1}$, involves a combination of 1,2-H shifts and the crucial ring closure/ring opening event, $\mathbf{7 \rightarrow 8} \rightarrow \mathbf{1 3}$. A general view of the corresponding part of the calculated $0 \mathrm{~K}$ energy surface is presented in Scheme 11. It is important to note that the $0 \mathrm{~K}$ calculated endothermicity of the reaction $\mathbf{1} \rightarrow$ (cyclopentenyl cation $\left.+\mathrm{CH}_{3}\right), \mathbf{1 7},(106 \mathrm{~kJ} / \mathrm{mol})$ matches closely the $\Delta \mathrm{H}^{\circ}{ }_{0}$ value deduced from experimental $\Delta \mathrm{H}^{\circ}{ }_{298}(119 \mathrm{~kJ} / \mathrm{mol}$, Table 1). Furthermore, the isomerisation of $\mathbf{1}$ into $\mathbf{1 4}$ appears to involve transition structures close in energy to the products $\mathbf{1 7}$, a situation which strongly determine the kinetic behavior of $\mathbf{1}$ as depicted in the dissociation rate modeling section. 


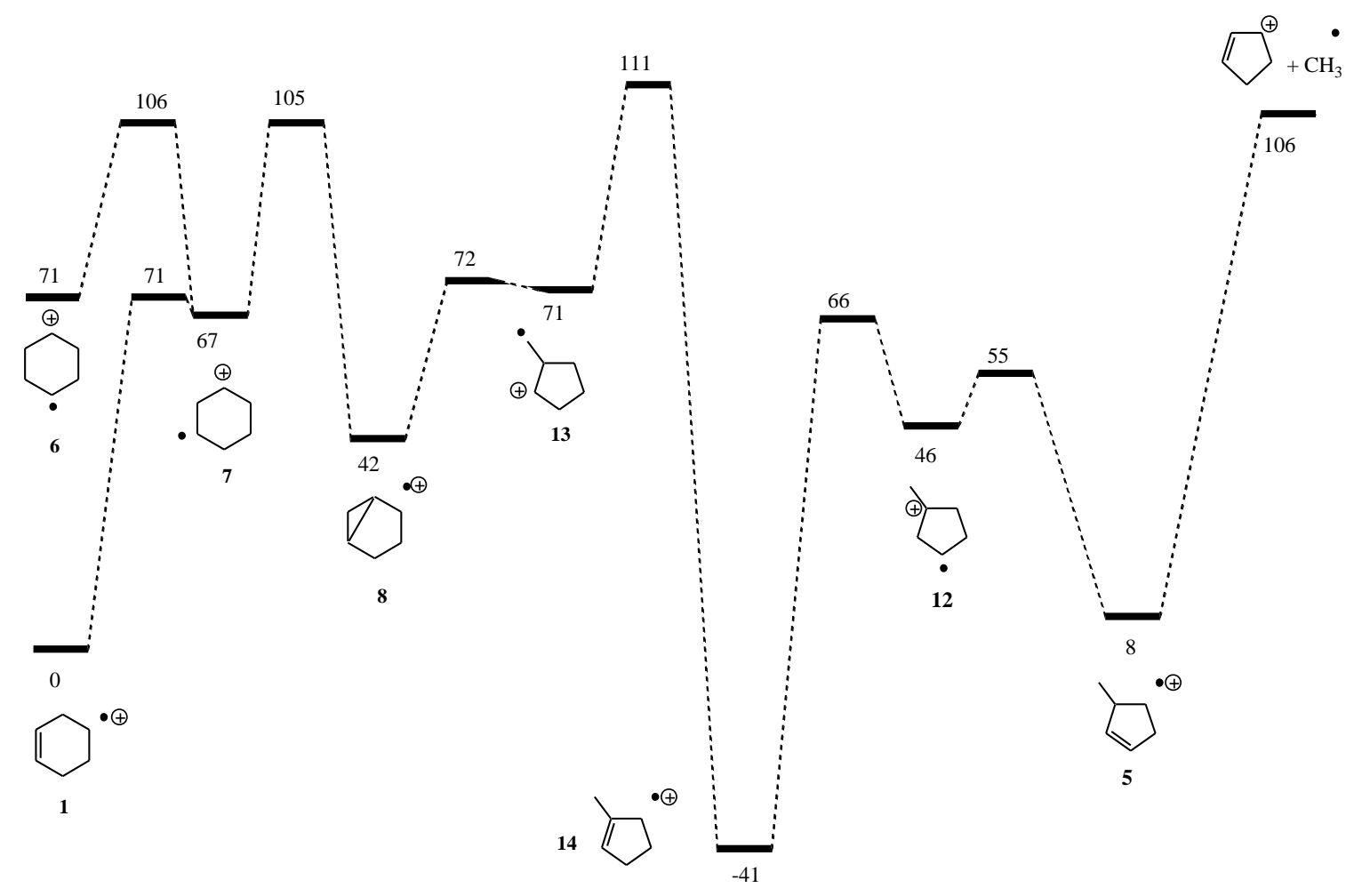

Scheme 11

The lowest energy route for the ethene loss from cyclohexene radical cation 1

The second dissociation reaction of ionized cyclohexene $\mathbf{1}$ is the retro Diels-Alder process. As recalled in the Introduction, this reaction has been extensively studied experimentally $^{11-16}$ and theoretically ${ }^{7,9,10}$. Thus, only the salient results will be indicated here. The most recent molecular orbital studies point to a potential energy surface connecting $\mathbf{1}$ and ionized 1,3-butadiene plus ethene, 18, via the distonic ion $\left[\mathrm{CH}_{2} \mathrm{CH}_{2} \mathrm{CHCHCHCH}_{2}\right]^{\bullet+}$, 2. According to $\mathrm{CCSD}(\mathrm{T}) / \mathrm{DZP}{ }^{9}$ or QCISD(T)/6-31G*10 calculations including ZPVE, the latter structure is situated $36^{9}-32^{10} \mathrm{~kJ} / \mathrm{mol}$ below $\mathbf{1}$ and the transition structure $\mathbf{1} / \mathbf{2}$ only $15^{9}-5^{10} \mathrm{~kJ} / \mathrm{mol}$ above 2 . Considering the relative $\Delta \mathrm{H}^{\circ}{ }_{0}$ value of 1 and 18 quoted in Table $1(169 \mathrm{~kJ} / \mathrm{mol})$ and the above mentioned molecular orbital data, the relevant part of the 0K energy surface may be constructed (see Scheme 12). Since the participation of ionized vinyl cyclobutane, 19, to the chemistry of $\mathbf{1}$ has been suggested $^{4,9,10}$, we present in Scheme 12 its calculated energy level $(118 \mathrm{~kJ} / \mathrm{mol})^{9}$ and that 
of the transition structure $\mathbf{2} \rightarrow \mathbf{1 9}$ which lies approximately $10 \mathrm{~kJ} / \mathrm{mol}$ above $\mathbf{2}^{9}$.

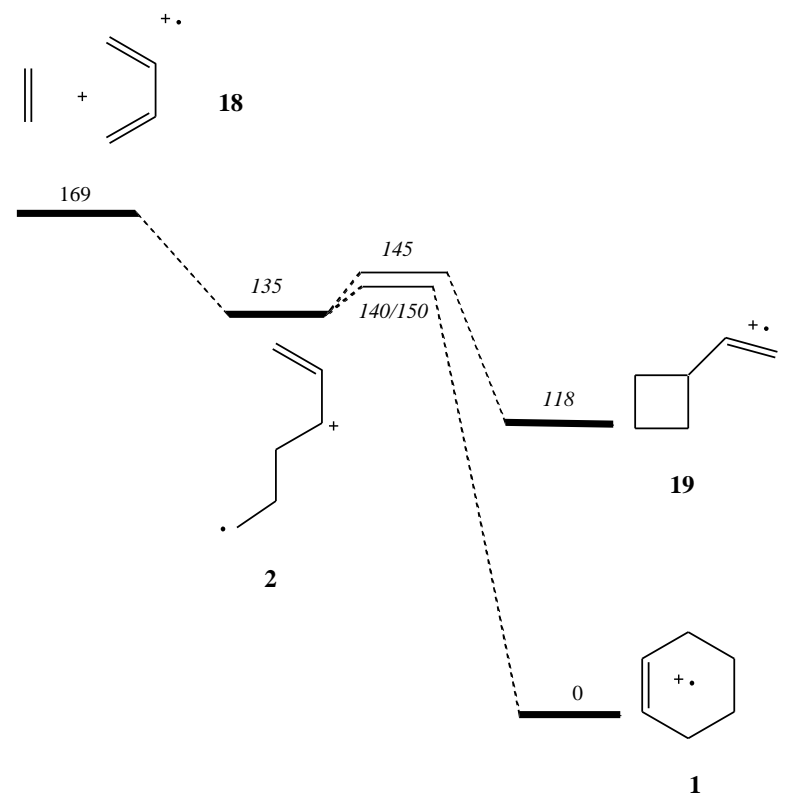

Scheme 12

Kinetics of cyclohexene radical cation dissociations

In order to examine the competition between the methyl and ethene losses from $\mathbf{1}$, unimolecular dissociation rates of both processes have been calculated using the RRKM theory. Considering the large number of steps of the studied reactions, a simplified approach of this system has been adopted.

Roughly, the potential energy profile along the $\mathrm{CH}_{3}$ loss coordinate is characterized by the deep valley created by 1-methyl cyclopentene radical cation 14 and by a large $1 \rightarrow 14$ isomerization barrier which presents the peculiarity to be close in energy to the dissociation products $\mathbf{1 7}$. We thus consider a simplified kinetic model where a reversible isomerisation step $\mathbf{1} \leftrightarrow \mathbf{1 4}$ precedes the dissociation $\mathbf{1 4} \rightarrow \mathbf{1 7}$. Each individual rate coefficient $\mathrm{k}_{\rightarrow_{\rightarrow}}{ }^{14}$, $\mathrm{k}_{14} \rightarrow^{1}$ and $\mathrm{k}_{14} \rightarrow^{17}$ have been calculated using the B3LYP/6-31G(d) frequencies and rotational constants summarized in Table 3 . For the isomerisation step $\mathbf{1} \leftrightarrow \mathbf{1 4}$ the transition structure considered is that of the energy determining 1,2-H shift, 13/14. Concerning the dissociation $\mathbf{1 4} \rightarrow \mathbf{1 7}$ we used the orbiting transition state model, which 
make use of the vibrational frequencies of the separated species, to estimate the corresponding rate constant. Critical energies were based on the experimental 0K energy difference between 1, 14 and 17 i.e. $-0.40 \mathrm{eV}$ and $1.23 \mathrm{eV}$ respectively (Table 1). Two values of the critical energy for the forward reaction $\mathbf{1} \rightarrow \mathbf{1 4}, \mathrm{E}^{\circ}$ (Scheme 13) were considered, the first one $\mathrm{E}^{\circ}=1.23 \mathrm{eV}$ comes from the evidence provided by the molecular orbital calculations that the transition structure $\mathbf{1 3 / 1 4}$ is close in energy to the products $\mathbf{1 7}$. Incidence of the lowering of this isomerization barrier $1 \leftrightarrow 14$ has been explored by using a critical energy $\mathrm{E}^{\circ}$ arbitrary equal to $1.13 \mathrm{eV}$. In order to estimate the overall dissociation rate for the process $1 \rightarrow 17, \mathrm{k}\left(\mathrm{CH}_{3}\right)$, it may be assumed that the steady state approximation is applicable to the vibrationally excited intermediate 14. Under these conditions, $\mathrm{k}\left(\mathrm{CH}_{3}\right)$ may be expressed as:

$$
\mathrm{k}\left(\mathrm{CH}_{3}\right)=\mathrm{k}_{1 \rightarrow 14} \cdot \mathrm{k}_{14 \rightarrow 17} /\left[\mathrm{k}_{1 \rightarrow 14},+\mathrm{k}_{14} \rightarrow^{1}+\mathrm{k}_{14} \rightarrow^{17}\right]
$$

Evolutions of the individual rate coefficient $\mathrm{k}_{1 \rightarrow} \rightarrow^{14}, \mathrm{k}_{14} \rightarrow^{1}, \mathrm{k}_{14} \rightarrow^{17}$ and of $\mathrm{k}\left(\mathrm{CH}_{3}\right)$ as a function of the internal energy $\mathrm{E}$ of the dissociating species $\mathbf{1}$ are displayed in Figure 1a.

\section{7}

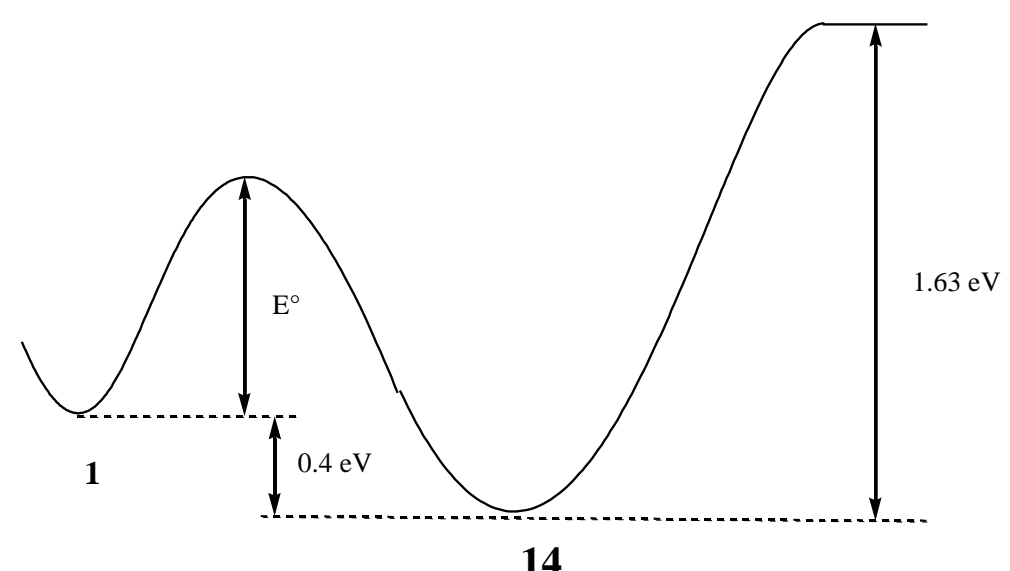

Scheme 13 (methyl loss)

Table 3

Figure 1 
It appears clearly from examination of Figure 1a that the inequality $\mathrm{k}_{1 \rightarrow 14}>\mathrm{k}_{14} \rightarrow{ }^{1}$ always holds. Similarly, $\mathrm{k}_{14} \rightarrow 17$ is significantly higher than $\mathrm{k}_{1 \rightarrow 14}$ because of the looseness of the transition state for separation of the products, $14 \rightarrow \mathbf{1 7}$, with respect to the isomerization step, $1 \rightarrow$ 14. As a consequence, the overall reaction rate $\mathrm{k}\left(\mathrm{CH}_{3}\right)$ is practically equal to $\mathrm{k}_{1 \rightarrow 14}$ i.e. to the rate coefficient of the slowest process. The two $\mathrm{k}\left(\mathrm{CH}_{3}\right)$ curves calculated for $\mathrm{E}^{\circ}=1.23$ and $1.13 \mathrm{eV}$ are reported in Figure 1c. It must be emphasized that $\mathrm{E}^{\circ}=1.23 \mathrm{eV}$ constitutes the upper bound for the critical energy of the isomerisation barrier en route to the methyl loss, thus the corresponding $\mathrm{k}\left(\mathrm{CH}_{3}\right)$ curve is the lowest limit for the methyl elimination rate. At this stage, it is of interest to consider the methyl loss process suggested to occur during the radical cation Diels-Alder reaction summarized in Scheme 3. According to Hofmann and Shaefer ${ }^{8}$, the rate determining step of the reaction is the 1,5-hydrogen migration $\mathbf{2} \rightarrow \mathbf{3}$, the transition structure of which being situated $187 \mathrm{~kJ} / \mathrm{mol}$ above 1. If we roughly consider the model of Scheme 13 with $\mathrm{E}^{\circ}=1.90 \mathrm{eV}$ the resulting reaction rate $\mathrm{k}\left(\mathrm{CH}_{3}\right)$ (Figure 1c) appears to be $10^{-5}$ to $10^{-2}$ lower than the limiting $\mathrm{k}\left(\mathrm{CH}_{3}\right)$ calculated with $\mathrm{E}^{\circ}=1.23 \mathrm{eV}$ in the explored energy range.

Concerning the retro Diels-Alder reaction, our kinetic modelling used the $1 \leftrightarrow 2 \rightarrow$ 18 sequence and the simplified potential energy profile sketched in Scheme 14. The 0K relative energies used in the calculations are based on the experimental enthalpy difference between 1 and 18 (1.75 eV, Table 1) and on the molecular orbital calculations of references 9 and 10, thus, two values of 1.45 and $1.55 \mathrm{eV}$ have been considered for the critical energy $\mathrm{E}^{\circ}$. As illustrated in Figure $1 \mathrm{~b}$, for both $\mathrm{E}^{\circ \prime}$ values, the rate constant for separation of the products $\mathrm{k}_{2 \rightarrow 18}$ is found to be larger than $\mathrm{k}_{2 \rightarrow 1}$ and $\mathrm{k}_{1 \rightarrow 2}$. Consequently, the overall rate constant for the retro Diels-Alder (RDA) reaction, given, in the assumption of the steady state approximation on intermediate ion $\mathbf{2}$, by the expression:

$$
\mathrm{k}(\mathrm{RDA})=\mathrm{k}_{1 \rightarrow^{2}} \cdot \mathrm{k}_{2} \rightarrow^{18} /\left[\mathrm{k}_{1} \rightarrow^{2}+\mathrm{k}_{2} \rightarrow^{18}+\mathrm{k}_{2} \rightarrow^{1}\right]
$$

may be equated to $\mathrm{k}_{1 \rightarrow}{ }^{2}$. The two relevant $\mathrm{k}(\mathrm{RDA})$ curves obtained with $\mathrm{E}^{\circ \prime}=1.45$ and 1.55 $\mathrm{eV}$ are presented in Figure 1c and compared with the $\mathrm{k}\left(\mathrm{CH}_{3}\right)$ results. 


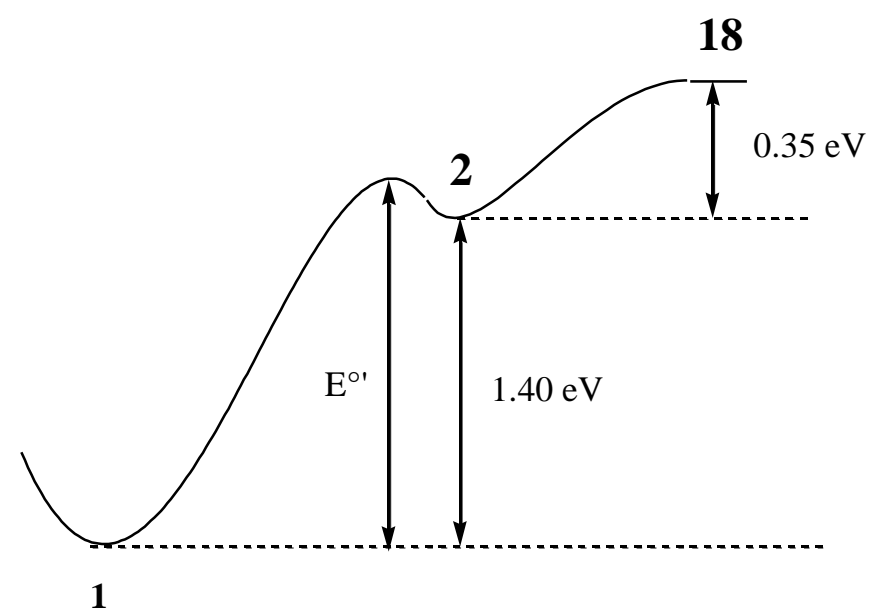

Scheme 14 (ethene loss)

The results of these kinetic modeling should be now compared with the experimental information. It has been observed from field ionization kinetic experiments ${ }^{11-13}$ that the retro Diels Alder reaction dominates for ions 1 of high internal energy while at low internal energy the predominant process is the elimination of the methyl radical. Moreover, the average rate constant for the two dissociation reactions were shown to be equal at a time close to $10^{-9} \mathrm{~s}$. In line with these observation, the major unimolecular dissociation of metastable ions $\mathbf{1}$, in the field free region of a magnetic tandem mass spectrometer, is the methyl loss ${ }^{14,15}$. Finally, when the 1,3-butadiene radical cation and ethene are allowed to react at thermal energies in a Fourier transform mass spectrometer, a branching ratio of 1.5 favoring methyl loss has been observed ${ }^{4}$. Under these experimental conditions, the sampled species correspond to ions 1 containing $~ 2.0 \mathrm{eV}$ internal energy.

All these findings are clearly verified here by the evolution of $\mathrm{k}(\mathrm{RDA})$ and $\mathrm{k}\left(\mathrm{CH}_{3}\right)$ presented in Figure $1 \mathrm{c}$ with $\mathrm{E}^{\circ}=1.23 \mathrm{eV}$ and $\mathrm{E}^{\circ}=1.45 \mathrm{eV}$. It is remarkable that the $\mathrm{k}(\mathrm{RDA})$ and $\mathrm{k}\left(\mathrm{CH}_{3}\right)$ curves crossing occurs for rate constant values of $\sim 10^{9} \mathrm{~s}^{-1}$ i.e. for observation time of ca. $10^{-9} \mathrm{~s}$ thus corroborating the field ionization kinetic results. The close evolution of both rate constants confirms that the $\mathrm{CH}_{3}$ loss is preceded by a rate determining step of transition state energy close to that of the dissociation products $\mathbf{1 7}$. From this point of view, it seems unlikely that a reaction preceded by a 1,5-hydrogen migration of $1.90 \mathrm{eV}$ critical energy should compete, at neither internal energy E, with the $\mathrm{CH}_{3}$ loss process described 
here (Figure 1c).

\section{H/D exchanges in labeled species}

Deuterium labeling experiments show that both eliminations of $\mathrm{CH}_{3}$ or $\mathrm{C}_{2} \mathrm{H}_{4}$ from ions 1 of low internal energy are accompanied by complete H/D scrambling ${ }^{11-15}$. According to the present molecular orbital calculations, the mechanism responsible of this phenomenon is the reversible 1,2-hydrogen shift $\mathbf{1} \leftrightarrow \mathbf{7}$, not the degenerate 1,3-hydrogen migration $\mathbf{1} \leftrightarrow \mathbf{1}$ originally suggested ${ }^{11}$ which may be clearly excluded on energetic grounds. It is of interest to note that a complete H/D scrambling has been also observed for the methyl elimination during the reaction between the 1,3-butadiene radical cation and ethene ${ }^{4}$, thus suggesting the passage through 1 before the $\mathrm{CH}_{3}$ elimination. By contrast, the selectivity observed during the same experiments for the $\mathrm{C}_{2} \mathrm{H}_{4}$ loss is obviously originating from competition with another process bypassing ionized cyclohexene 1. From a mechanistic point of view, a [2+1] cycloaddition/cycloreversion reaction involving ionized vinylcyclobutane, 19, offers a simple explanation of the fact that the eliminated $\mathrm{C}_{2} \mathrm{H}_{4}$ contains a methylene group from the terminal position of both reactants ${ }^{4}$. Results of molecular orbital calculation $^{9,10}$ (Scheme 12) suggest that after its formation from the reactants 18, the distonic ion $\mathbf{2}$ isomerise equivalently (and easily) to 1 or 19 but that the back reaction occurs more readily from 19 than from 1 since the critical energies differ by $118 \mathrm{~kJ} / \mathrm{mol}$.

\section{Conclusion}

The present B3LYP/6-311+G(3df,2p)//B3LYP/6-31G(d) molecular orbital calculations combined with RRKM statistical reaction rate estimations shed a new light in the ionized cyclohexene chemistry. First, the energetic and mechanistic aspects of the methyl loss process from cyclohexene radical cation, $\mathbf{1}$, or reaction between ionized butadiene and ethene have been established. Methyl loss is demonstrated to result from successive 1,2-hydrogen shifts and ring-contraction/ring-opening steps involving, as a crucial 
intermediate, ionized bicyclo $[1,3,0]$ hexane. This reaction mechanism is presently the process of lowest energy identified at that time. It is the lone compatible with the appearance energy determinations. It is also probably the best candidate for the explanation of the methyl loss observed during the cation radical Diels-Alder reaction.

Second, the kinetic modeling of the retro Diels-Alder reaction from 1 shows that the first step, the formation of the distonic ion $\left[\mathrm{CH}_{2} \mathrm{CH}_{2} \mathrm{CHCHCHCH}_{2}\right]^{++}$, is crucial in lowering the rate constant values $\mathrm{k}(\mathrm{RDA})$ to a level comparable to that of the methyl loss, $\mathrm{k}\left(\mathrm{CH}_{3}\right)$. This competition, attested by various experimental results (branching ratio, H/D exchanges, appearance energy determination) concerning cyclohexene radical cation, 1, or reaction between ionized butadiene and ethene is satisfactorily reproduced by the present theoretical findings.

\section{Acknowledgement}

The authors thank Professor Tomas Baer for the communication of his PEPICO results on cyclohexene and 3-methyl cyclopentene and Professor Olaf Wiest for the vibrationnal frequencies of the transition structure $\mathbf{1 / 2}$. This research has been partially supported by the DGI Project No. BQU2003-00894. 


\section{References}

1 For a review on radical cation cycloadditions in the condensed phase see:

Bauld, N. L. Tetrahedron 1989, 45, 5307-5363.

2 For examples of the application of radical cation cycloadditions to organic synthesis see the literature cited in references 7-9 and the more recent studies:

a) Peglow, T.; Blechert, S.; Steckhan, E. Chem. Eur. J. 1998, 4, 107-112.

b) Peglow, T.; Blechert, S.; Steckhan, E. Chem. Commun. 1999, 4, 433-434.

c) Rößler, U; , T.; Blechert, S.; Steckhan, E. Tet. Lett. 1999, 4, 7075-7078.

d) Saettel, N. J.; Oxgaard, J.; Wiest, O. Eur. J. Org. Chem 2001, 1429-1439.

e) Saettel, N. J.; Wiest, O.; Singleton, D. A.; Meyer, M. P. J. Am. Chem. Soc. 2002, 124, 11552-11559.

3 For a review on radical cation cycloadditions in the gas phase see:

Dass, C. Mass Spectrom Rev. 1990, 9, 1- .

4 Bouchoux, G.; Salpin, J-Y. Rapid. Commun.Mass Spectrom, 1994, 8, 325-328.

5 Bouchoux, G.; Salpin, J-Y. Chem. Phys. Lett, 2002, 366, 510-519.

$6 \mathrm{Hu}, \mathrm{H}$; Wenthold, P. G. J. Phys. Chem. A 2002, 106, 10550-10553

7 Bauld, N. L. J. Am. Chem .Soc. 1992, 114, 5800-5804.

8 Hofmann, M.; Schaefer, H. F. I. J. Phys. Chem. A 1999, 103, 8895-8905.

9 Hofmann, M.; Schaefer, H. F. I. J. Am. Chem. Soc. 1999, 121, 6719-6729.

10 Haberl, U.; Wiest, O.; Steckhan, E. J.Am.Chem.Soc. 1999, 121, 6730-6736.

11 Derrick, P. J.; Falick, A. M.; Burlingame, A. L. J. Am. Chem. Soc. 1972, 94, 6794-6802.

12 Burinsky, D. J.; Glish, G. L.; Cooks, R. G.; Zwinselman, J. J.; Nibbering, N. M. M. J. Am. Chem. Soc. 1981, 103, 465-467.

13 Nibbering, N. M. M. Mass Spectrom. Rev. 1984, 3, 445-477. 
14 Wolkoff, P.; Holmes, J. L. Can. J. Chem.. 1979, 57, 348-354.

15 Wolkoff, P.; Holmes, J. L. Can. J. Chem.. 1980, 58, 251-257.

16 Hu, H.; Wenthold, P. G. J. Am. Soc. Mass Spectrom. 2001, 12, 840-845.

17 Winters, R. E.; Collins, J. H. Org. Mass Spectrom. 1969, 2, 299-308.

18 Praet, M. T. Org. Mass Spectrom. 1970, 4, 65-80.

19 Lossing F. P.; Traeger J. C. Int. J. Mass Spectrom. Ion Phys. 1976, 19, 9-22.

20 Baer, T. personal communication, 2003.

21 Gaussian 98, Revision A.6, Frisch, M. J.; Trucks, G. W.; Schlegel, H. B.; Scuseria, G. E.;

Robb, M. A.; Cheeseman, J. R.; Zakrzewski, V. G.; Montgomery, J. A.; Stratmann, Jr. R. E.; Burant, J. C.; Dapprich, S.; Millam, J. M.; Daniels, A. D.; Kudin, K. N.; Strain, M. C.; Farkas, O.; Tomasi, J.; Barone, V.; Cossi, M.; Cammi, R.; Mennucci, B.; Pomelli,C.; Adamo, C.; Clifford, S.; Ochterski, J.; Petersson, G. A.; Ayala, P. Y.; Morokuma, Q. Cui K.; Malick, D. K.; Rabuck, A. D.; Raghavachari, K.; Foresman, J. B.; Cioslowski, J.; Ortiz, J. V.; Stefanov, B. B.; Liu, G.; Liashenko, A.; Piskorz, P.; Komaromi, I.; Gomperts, R.; Martin, R. L.; Fox, D. J.; Keith, T.; Al-Laham, M. A.; Peng, C. Y.; Nanayakkara, A.; Gonzalez, C.; Challacombe, M.; Gill, P. M. W.; Johnson, B.; Chen, W.; Wong, M. W.; Andres, J. L.; Gonzalez, C.; Head-Gordon, M.; Replogle, E. S.; and Pople, J. A. Gaussian, Inc., Pittsburgh PA, 1998.

22 NIST webbook. http:// webbook.nist.gov/chemistry

23 Lias, S. G.; Bartmess, J. E.; Liebman, J. F.; Holmes, J. L.; Levin, R. D.; Mallard, W. G. Gas Phase Ion and Neutral Thermochemistry, J. Phys. Chem. Ref. Data Vol 17, suppl. 1, NSRDS: U.S. Government Printing Office: Washington, DC, 1988. 
Table 1: Relevant thermochemical data $(\mathrm{kJ} / \mathrm{mol})$

\begin{tabular}{|c|c|c|c|c|}
\hline Species & $\Delta_{\mathrm{f}} \mathrm{H}^{\circ}{ }_{298}$ & relative $\Delta \mathrm{H}^{\circ}{ }_{298}$ & $\Delta_{\mathrm{f}} \mathrm{H}_{0}^{\circ}$ & relative $\Delta \mathrm{H}_{0}^{\circ}$ \\
\hline${\text { [cyclohexene }]^{+}}^{+}$ & $859.2 \pm 1.4^{a}$ & 0 & $890.5^{b}$ & 0 \\
\hline [cyclopentenyl] $^{+}$ & $840.6 \pm 4.1^{d}$ & & $860.8^{b}$ & \\
\hline $\mathrm{CH}_{3}$ & $145.7^{c}$ & & $149.0^{c}$ & \\
\hline cyclopentenyl] $^{+}+\mathrm{CH}_{3}$ & 986.3 & 127.1 & 1009.8 & 119.4 \\
\hline$[1,3 \text {-butadiene }]^{+}$ & $984.1 \pm 1.1^{e}$ & & $998.61^{b}$ & \\
\hline $\mathrm{C}_{2} \mathrm{H}_{4}$ & $52.5^{c}$ & & $60.7^{c}$ & \\
\hline $\begin{array}{l}{[1,3 \text {-butadiene }]^{++}+} \\
\mathrm{C}_{2} \mathrm{H}_{4}\end{array}$ & 1036.6 & 177.4 & 1059.3 & 168.8 \\
\hline \multicolumn{5}{|c|}{$\begin{array}{l}\text { a. From IE }(\text { cyclohexene })=8.95 \pm 0.1 \mathrm{eV} \text { and } \Delta_{\mathrm{f}} \mathrm{H}^{\circ}{ }_{298}(\text { cyclohexene })=-4.3 \pm 1.0 \mathrm{~kJ} / \mathrm{mol} \text { (ref. 22) } \\
\text { b. Calculated using } \mathrm{H}^{\circ}{ }_{298}-\mathrm{H}^{\circ}{ }_{0} \text { corrections estimated at the } \mathrm{B} 3 \mathrm{LYP} / 6-31 \mathrm{G}(\mathrm{d}) \text { level and } 1.05 \text { and } 8.47 \mathrm{~kJ} / \mathrm{mol} \text { for the } \\
\text { elements } \mathrm{C}(\text { graphite }) \text { and } \mathrm{H}_{2}(\mathrm{~g}) \text {, respectively. } \\
\text { c. From reference 23. } \\
\text { d. From reference 5; } \\
\left.\text { e. From IE }(1,3 \text {-butadiene })=9.072 \pm 0.007 \mathrm{eV} \text { and } \Delta_{\mathrm{f}} \mathrm{H}^{\circ}{ }_{298}(1,3 \text {-butadiene })=108.8 \pm 0.8 \mathrm{~kJ} / \mathrm{mol} \text { (ref. } 22\right)\end{array}$} \\
\hline
\end{tabular}


Table 2. Total energies (E, hartrees), zero point energies (ZPE, hartrees) and relative $0 \mathrm{~K}$ energies $(\Delta \mathrm{E}, \mathrm{kJ} / \mathrm{mol})$ of the $\left[\mathrm{C}_{6} \mathrm{H}_{10}\right]^{++}$structures investigated.

\begin{tabular}{|c|c|c|c|}
\hline$\left[\mathrm{C}_{6} \mathrm{H}_{10}\right]^{*+}$ species & $E^{a}$ & $\mathrm{ZPE}^{\mathrm{b}}$ & $\Delta \mathrm{E}$ \\
\hline 1 & -234.408695 & 0.143570 & 0 \\
\hline 7 & -234.380150 & 0.140795 & 67 \\
\hline 6(planar) & -234.378971 & 0.140961 & 71 \\
\hline 6(chair) & -234.383588 & 0.144020 & 67 \\
\hline 8 & -234.393378 & 0.144210 & 42 \\
\hline 9 & -234.348211 & 0.143382 & 158 \\
\hline 5 & -234.404034 & 0.142041 & 8 \\
\hline 14 & -234.421868 & 0.141105 & -41 \\
\hline 15 & -234.401535 & 0.142195 & 15 \\
\hline 13 & -234.381160 & 0.143242 & 71 \\
\hline 11 & -234.360186 & 0.140480 & 119 \\
\hline 16 & -234.339710 & 0.142557 & 178 \\
\hline 12 & -234.385176 & 0.137614 & 46 \\
\hline 10 & -234.375028 & 0.141834 & 84 \\
\hline $\mathrm{C}_{5} \mathrm{H}_{7}{ }^{+}$ & -194.451352 & 0.104608 & \\
\hline $\mathrm{CH}_{3}{ }^{\circ}$ & -39.8577429 & 0.029833 & \\
\hline $\mathrm{C}_{5} \mathrm{H}_{7}^{+}+\mathrm{CH}_{3}$ & -234.359095 & 0.134441 & 106 \\
\hline $\mathrm{C}_{4} \mathrm{H}_{6}{ }^{++}$ & -155.730256 & 0.084927 & \\
\hline $\mathrm{C}_{2} \mathrm{H}_{4}$ & -78.621085 & 0.051228 & \\
\hline $\mathrm{C}_{4} \mathrm{H}_{6}{ }^{*+}+\mathrm{C}_{2} \mathrm{H}_{4}$ & -234.351341 & 0.136155 & 131 \\
\hline $1 / 7$ & -234.378622 & 0.140489 & 71 \\
\hline $6 / 7$ & -234.364372 & 0.139909 & 106 \\
\hline $6 / 6$ & $-234 . .37855$ & 0.141491 & 74 \\
\hline $7 / 8$ & -234.365678 & 0.140975 & 106 \\
\hline $8 / 9$ & -234.336546 & 0.142535 & 187 \\
\hline $9 / 15$ & -234.347578 & 0.142942 & 159 \\
\hline $13 / 14$ & -234.361678 & 0.139287 & 111 \\
\hline $13 / 16$ & -234.331460 & 0.141870 & 198 \\
\hline $11 / 13$ & -234.351504 & 0.139036 & 138 \\
\hline $11 / 12$ & -234.338336 & 0.138459 & 171 \\
\hline $11 / 15$ & -234.352164 & 0.140715 & 141 \\
\hline $14 / 12$ & -234.378560 & 0.138686 & 66 \\
\hline $5 / 12$ & -234.382834 & 0.138659 & 55 \\
\hline $8 / 13$ & -234.381073 & 0.142889 & 72 \\
\hline ts610 & -234.370366 & 0.141808 & 96 \\
\hline ts16 & -234.353493 & 0.140825 & 138 \\
\hline
\end{tabular}

${ }^{a}$ B3LYP/6-311+G(3df,2p)//B3LYP/6-31G(d) level

${ }^{\mathrm{b}}$ B3LYP/6-31G(d) level, (without scaling). 